\title{
Red-legged kittiwake feathers link food availability to environmental changes in the Bering Sea
}

\author{
Alexis P. Will*, Evgenia V. Kitaiskaia, Alexander S. Kitaysky \\ Institute of Arctic Biology, University of Alaska Fairbanks, Fairbanks, AK 99775, USA
}

\begin{abstract}
The largest breeding population of red-legged kittiwakes Rissa brevirostris has undergone a dramatic decline and subsequent recovery since 1975. The causal mechanism is hypothesized to be climate-induced food shortages during reproduction, yet little is known about how the basin ecosystem, where breeding red-legged kittiwakes primarily forage, is affected by climate variability. We examined when and under what conditions red-legged kittiwakes experienced food shortages. Head feathers (winter) and first primary feathers (summer; $\mathrm{n}=24$ and $27 \mathrm{yr}$, and 194 and 122 individuals, respectively) were collected between 1913 and 2016 on St. George Island and were analyzed for stable isotope signatures of carbon $\left(\delta^{13} \mathrm{C}\right)$, nitrogen $\left(\delta^{15} \mathrm{~N}\right)$, and sulfur $\left(\delta^{34} \mathrm{~S}\right)$. Feathers were also analyzed for corticosterone concentration (fCORT), which indicates a bird's exposure to nutritional stress during feather growth. Summer fCORT concentrations were lower when values of the annual Pacific Decadal Oscillation index were positive. Winter fCORT concentrations and $\delta^{15} \mathrm{~N}$ signatures increased when February sea-ice coverage was extensive. We conclude that, since 1913, warm conditions in the Bering Sea ecosystem have been associated with low nutritional stress in adult red-legged kittiwakes breeding on St. George Island. However, we found no strong evidence for isotopic shifts over this same period. A better understanding of the factors governing the abundance and availability of red-legged kittiwakes' prey is needed to predict the impact of anticipated warming on this species and its foraging habitat.
\end{abstract}

KEY WORDS: Historical ecophysiology · Feather corticosterone · St. George Island · Stable isotope analysis $\cdot$ Food shortage $\cdot$ Nutritional stress.

\section{INTRODUCTION}

The Bering Sea climate has historically varied between 'warm' and 'cold' states, characterized by changes in winter sea-ice dynamics, winter storminess, and summer water temperatures (Rodionov \& Overland 2005). Fluctuations in the region's animal populations and community structure have been associated with these changes in climate (Hare \& Mantua 2000, Litzow \& Mueter 2014). In the southeastern Bering Sea, population declines observed in seabird, marine mammal, and fish populations (Hare \& Mantua 2000, Litzow \& Mueter 2014) during the late 1970s and 1980s are hypothesized to have been a result of changes in food availability (Anonymous

\footnotetext{
${ }^{*}$ Corresponding author: awill4@alaska.edu
}

1993). How food availability changed, however, is not certain.

One hypothesis posited that a coinciding explosion in the walleye pollock Gadus chalcogrammus (hereafter 'pollock') population resulted in increased competition with other top predators for forage fishes (Springer 1992). Another proposed that oceanographic conditions were no longer suitable for lipid-rich forage fish species and fish lower in lipid content, such as the now abundant juvenile pollock, were inadequate to meet the energy demands of predatory fish, seabird, and marine mammal populations (Alverson 1992, the 'junk food hypothesis'). Another hypothesis, not yet tested, is that food shortages occurred during the winter and affected seabirds and marine

(C) The authors 2018. Open Access under Creative Commons by Attribution Licence. Use, distribution and reproduction are unrestricted. Authors and original publication must be credited. 
mammals outside of the reproductive season (e.g. during migration or overwintering, Renner et al. 2014).

In terms of seabird responses to climate-driven food availability, much work has been done to understand how climate-associated changes in the southeastern Bering Sea continental shelf ecosystem affect prey abundance (e.g. Napp et al. 2000, Springer et al. 2007, Hunt et al. 2011) and seabird reproduction (e.g. Springer 1998, Murphy et al. 2016). How or whether these same climate patterns affect forage fish production in the Bering Sea deep water basin is less clear. Of the seabirds breeding in the southeastern Bering Sea, red-legged kittiwakes Rissa brevirostris are the only fish-eating seabird that relies primarily on oceanic prey (Byrd \& Williams 1993). Red-legged kittiwakes forage primarily on myctophids, mesopelagic fishes, during the reproductive season (Storer 1987, Byrd \& Williams 1993). Thus, red-legged kittiwakes might be somewhat independent of the food dynamics of the southeastern Bering Sea continental shelf region, which govern the diets of other seabirds breeding on the Pribilof Islands (Renner et al. 2012).

The breeding population of red-legged kittiwakes on St. George Island, where 80 \% of the world's population breeds, has shown dramatic changes in its population trajectory over the past 4 decades (Tappa \& Romano 2017), suggesting that the birds are experiencing changes in prey availability at some point in their annual cycle. Changes in the environment can result in food shortages that are reflected in seabird physiology (e.g. Kitaysky et al. 1999, Satterthwaite et al. 2012). Nutritional stress incurred during reproduction affects adult seabird survival (Kitaysky et al. 2007, 2010, Satterthwaite et al. 2010) and poorquality food fed to developing offspring may produce low-quality individuals that may be unable to recruit into the population (Kitaysky et al. 2006). There is some evidence that red-legged kittiwake reproductive success may be attributed to environmental conditions (Springer 1998), but a connection between environmental variability and food availability has yet to be made. We hypothesized that further examination of the trophic ecology of red-legged kittiwakes over time might provide insight into changes in the Bering Sea basin's ecosystem in response to environmental variability.

As a step towards resolving the relationship between changes in environmental conditions and the responses of red-legged kittiwakes, we used a historical ecophysiology approach to examine the isotopic signatures and physiological response of St. George Island red-legged kittiwakes to environmental variability from 1912 to 2016. Historical ecophysiology uses analytical tools to mine ecologically relevant measures from specimens or samples collected in the past, allowing researchers to greatly extend time series and rely on unified laboratory methodologies (e.g. Charapata 2016).

Red-legged kittiwakes undergo 2 annual molts. Towards the end of the breeding season ( July-August), adults initiate their flight feather molt, a sequential molt that begins with the loss of their first primary feathers (Byrd \& Williams 1993). In approximately February, adults undergo a pre-nuptial molt where they replace their non-breeding head feather plumage (Gabrielson \& Lincoln 1959). To characterize foraging conditions during the breeding (summer) and nonbreeding (winter) periods, we analyzed first primary ('primary') and head feathers for nitrogen, carbon, and sulfur stable isotope ratios. Based on the ratio of heavy (rare) to light (common) isotopes in an organism's tissues and differential isotopic incorporation rates, it is possible to identify the trophic level (nitrogen) and foraging location (i.e. offshore vs. onshore or benthic vs. pelagic, measured by carbon and sulfur) of the organism in a marine food web (Fry 1988).

Changes in a marine organism's nitrogen stable isotope ratio over time may indicate changes in prey species consumed (lower values indicate it is foraging on lower-trophic-level prey, Peterson \& Fry 1987), changes in food web structure (the prey species may be the same but the food web has reorganized so that the trophic level it occupies changes, Grecian et al. 2016), or changes in the baseline nitrogen stable isotope ratio due to physical processes (for example, the mixed-layer depth and presence or strength of eddies can affect the amount of particulate organic matter available to nitrate-dependent phytoplankton, Yang et al. 2017). In the Bering Sea, carbon stable isotope ratios increase from the ocean basin to the continental shelf (Schell et al. 1998), and can be used to identify changes in the amount and composition of primary producers (Grebmeier et al. 2006). At the multidecadal timescale, however, carbon stable isotope values may decrease $(-0.1$ to $-0.2 \%$ per decade in subpolar regions, Eide et al. 2017) due to the dilution of ${ }^{13} \mathrm{C}$ in the atmosphere by the burning of fossil fuels (the Suess effect, Revelle \& Suess 1957). Sulfur stable isotope ratios are less susceptible to large changes from anthropogenic activities (Peterson \& Fry 1987) and complement carbon stable isotope values in detecting shifts in sources of primary production in marine food webs (Connolly et al. 2004). In the marine system, higher sulfur stable isotope values indicate the incorporation of nutrients from more benthic habitats (Peterson \& Fry 1987). 
While stable isotope analysis can be used to characterize how diet and food web organization may have changed over time, it does not fully capture how seabirds may be affected by changes in the environment. A change in conditions may be detrimental to seabirds but may not be accompanied by a shift in isotopic signatures. For example, prey may become more dispersed or less available and require more energy to obtain (Will et al. 2015). Alternatively, isotopic signatures may shift when birds switch prey types but experience no change in caloric intake, or they may shift between equidistant foraging locations. Both instances would result in changes in stable isotope values but may have no effect on the birds themselves. Therefore, we also analyzed feathers for corticosterone concentration. During molt, circulating corticosterone is deposited into the growing feather and provides an integrated measure of the nutritional stress a bird experienced during the period of feather growth (Bortolotti et al. 2008). Elevated concentrations of feather corticosterone have been experimentally linked to low food intake (Will et al. 2014), validated as a proxy for low food availability (Will et al. 2015), and do not degrade over time (Bortolotti et al. 2009).

Measuring nutritional stress in tandem with stable isotope analysis makes it possible to narrow down explanations for changes in stable isotope values over time. For example, if nitrogen stable isotope ratios increase and nutritional stress decreases, the changes in nitrogen may be attributed to increased prey quality, or consumption of a higher-trophic- level prey species, and interpreted as being beneficial (Oelbermann \& Scheu 2002). Conversely, if nutritional stress increases, the increase in nitrogen stable isotope ratios may be due to starvation and interpreted as detrimental (Cherel et al. 2005). We modeled changes in stable isotope values and nutritional stress in response to environmental parameters over a multidecadal timescale to determine whether redlegged kittiwakes experienced food shortages during the winter, as well as during the summer, and under what environmental conditions these shortages occurred.

\section{MATERIALS AND METHODS}

\section{Study site and specimen origin}

All samples were collected from adult red-legged kittiwakes that had been breeding on St. George Island, one of the Pribilof Islands, in the southeastern Bering Sea $\left(56.58^{\circ} \mathrm{N}, 169.60^{\circ} \mathrm{W}\right.$, Fig. 1). We sampled live birds $(n=77)$, and specimens $(n=103)$ from the following museums: Carnegie Museum of Natural History, Natural History Museum of Los Angeles County, Museum of Southwestern Biology, James R. Slater Museum, San Diego Natural History Museum, and University of Alaska Fairbanks' Museum of the North (see Table S1 in the Supplement at www. int-res.com/articles/suppl/m593p261_supp.pdf for museum specimen IDs).

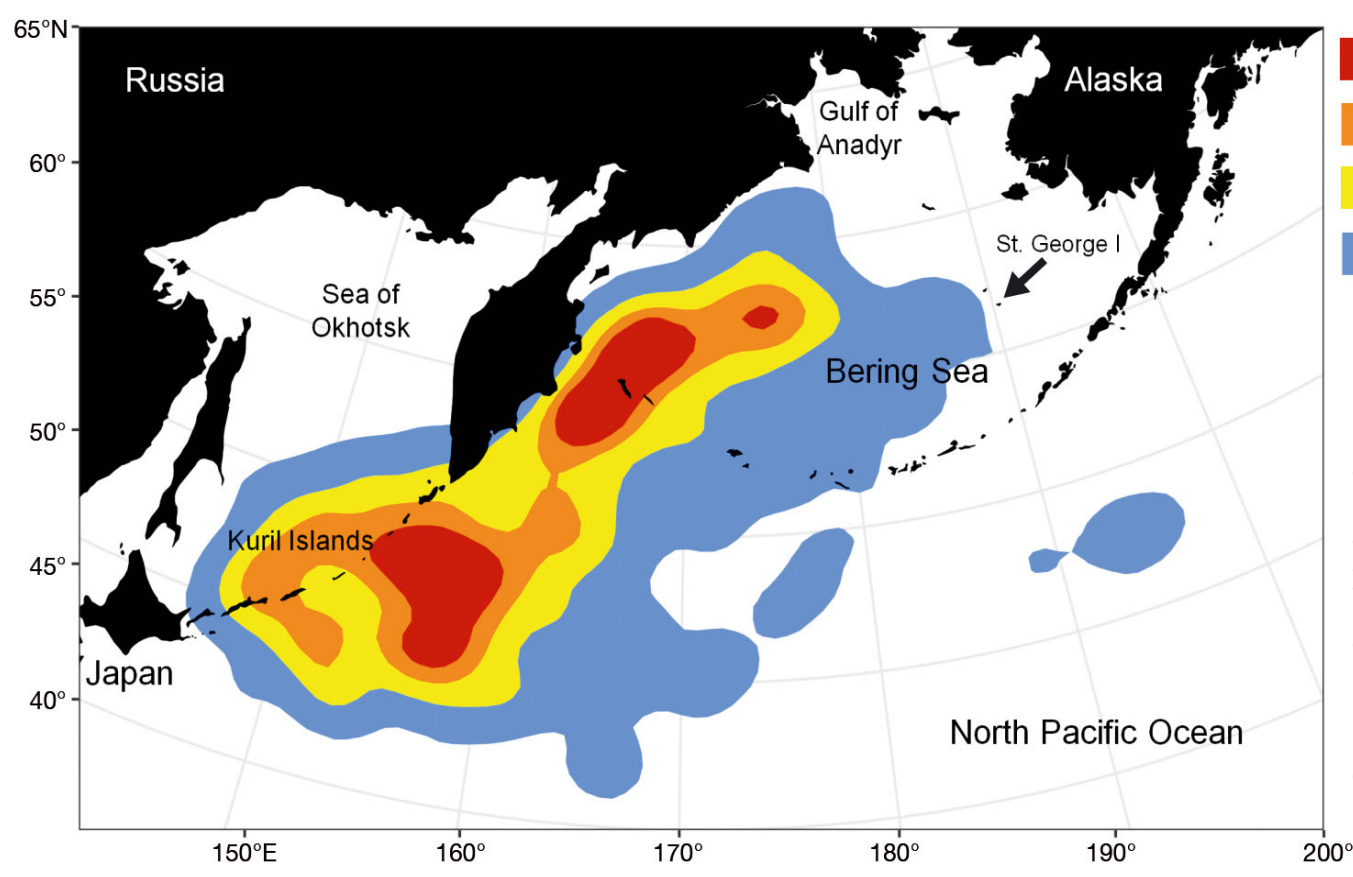

$25 \%$ UD

$50 \%$ UD

$75 \%$ UD

$95 \%$ UD

Fig. 1. Study site and distribution of red-legged kittiwakes during February. Shown are the $25,50,75$, and $95 \%$ utilization distributions (UD) of overwintering red-legged kittiwakes in February tracked during the winters of 20112012, 2014-2015, and 20152016 (Orben et al. 2018, this Theme Section). Map courtesy of R. A. Orben 


\section{Feather sampling}

To minimize the impact of our study on museum collections, we used only a small portion of a primary feather for our analyses, and whenever possible left the feather still attached to the museum skin. Specifically, we cut a $20 \mathrm{~mm}$ section, approx. $20 \mathrm{~mm}$ from the tip of the first primary along the proximal side of the vane to standardize feather samples across individuals (Harris et al. 2016). In the field, birds were captured using a noose pole, the first primary was clipped off at the base, and the same $20 \mathrm{~mm}$ section described above was later removed in the lab. For both museum and wild-caught birds, we plucked 3 head feathers between the upper nape and crown of the head (see Table S2 in the Supplement for samples by year).

\section{Corticosterone analysis}

We weighed and measured (head feathers only) feathers to the nearest $0.05 \mathrm{mg}$ and $0.5 \mathrm{~mm}$. We combined all 3 head feathers (measuring each separately but weighing them collectively) into a single sample for each individual (Lattin et al. 2011). We washed feather samples in isopropanol (HPLC grade, SigmaAldrich) by adding $1 \mathrm{ml}$ of isopropanol to a vial containing the feather sample, vortexed for $5 \mathrm{~s}$, and removed the isopropanol $50 \mathrm{~s}$ later. After the washing, we added $5 \mathrm{ml}$ of methanol (HPLC grade, Fisher Scientific) to each sample. We proceeded with extraction and analysis procedures reported elsewhere (see Bortolotti et al. 2008, Will et al. 2015) with the exception that samples were filtered via solid phase extraction (Bond Elut C18 cartridges, Agilent Technologies). We added $2000 \mathrm{cpm}$ (counts per minute) of radio-labeled corticosterone (PerkinElmer NET399) to each sample to account for losses of hormone during analysis. On average recoveries were $94.8 \%$.

Feathers were analyzed in 5 radioimmunoassays (Wingfield \& Farner 1975). Intra-assay CV was <1\% (range: 0.72 to $0.97 \%$ ) and inter-assay CV was $1.2 \%$. We standardized concentrations to sample mass (ng $\mathrm{g}^{-1}$ ) and feather length $\left(\mathrm{pg} \mathrm{mm}^{-1}\right.$, head feathers only).

\section{Stable isotope analysis}

Typically feathers are washed in a 2:1 chloroform: methanol solution to remove dirt and oils from the feather's surface prior to stable isotope analysis
(Dobush et al. 1985). In this study, feathers were washed of dirt and surface oils during the isopropanol wash followed by sonication and overnight extraction in methanol at $50^{\circ} \mathrm{C}$. Corticosterone is a cholesterol-based hormone, thus the $12 \mathrm{~h}$ methanol extraction process is targeted specifically at removing fats from within the feather matrix (Bortolotti et al. 2008). Therefore, after the methanol extraction, feathers had been effectively washed and were ready for stable isotope analysis (mean primary $\mathrm{C}: \mathrm{N}$ ratio $=3.16$, mean head $\mathrm{C}: \mathrm{N}$ ratio $=$ 3.06, pure protein $\sim 3.5 \%$, Cherel et al. 2014). We weighed out 0.6 to $1.0 \mathrm{mg}$ (carbon and nitrogen) or 2.3 to $3.2 \mathrm{mg}$ (sulfur) of pulverized primary feather tissues, or a single intact head feather, and loaded the sample material into a tin boat. Stable isotope analyses for carbon and nitrogen were conducted at the Alaska Stable Isotope Facility (ASIF, Fairbanks AK), while analyses for sulfur was conducted at the Colorado Plateau Stable Isotope Laboratory (CPSIL, Flagstaff, AZ). All primary samples were analyzed for all 3 isotopes. There were no head feathers for sulfur analysis for 2005, and a subset of samples was analyzed for the years 2011, 2015, and 2017 (17 samples from 2011 were analyzed, 8 from 2015, and 8 from 2016). Briefly, samples were loaded into an auto-sampler, which dropped them into an elemental analyzer (EA Costech ECS 4010) interfaced with a Delta+XP Thermo Electron isotope ratio mass spectrometer.

We used delta notation to express stable isotope ratios, ' $R$ ', compared with PeeDee Belamnite (carbon), atmospheric nitrogen, and Canyon Diablo Triolite (sulfur; $\delta \mathrm{X}=R_{\text {sample }} / R_{\text {standard }}$ ). At ASIL, peptone was used as an internal standard and analyses were completed in 4 separate runs. Inter-run standards were within $\pm 0.01 \%$ for both $\delta^{15} \mathrm{~N}$ and $\delta^{13} \mathrm{C}$, and on average intra-run standards were within $\pm 0.1 \%$ for both $\delta^{15} \mathrm{~N}$ and $\delta^{13} \mathrm{C}$. Head feathers from 2010 and 2011 were analyzed by Orben et al. (2015) at the University of California Santa Cruz (UCSC); UCSC internal standards $\left(\delta^{15} \mathrm{~N}\right.$ mean $=5.38, \mathrm{SD}=0.09 ; \delta^{13} \mathrm{C}$ mean $=-12.61, \mathrm{SD}=0.16 ; \mathrm{n}=16$ ) were comparable $\left(\delta^{15} \mathrm{~N}: t_{26}=-0.72, \mathrm{p}=0.48 ; \delta^{13} \mathrm{C}: t_{26}=0.32, \mathrm{p}=0.75\right)$ when run at $\operatorname{ASIF}\left(\delta^{15} \mathrm{~N}\right.$ mean $=5.39, \mathrm{SD}=0.07 ; \delta^{13} \mathrm{C}$ mean $=-12.56, \mathrm{SD}=0.21 ; \mathrm{n}=12$ ). Samples analyzed for sulfur stable isotope ratios were completed in 5 separate runs and were standardized against 6 International Atomic Energy Agency reference standards (IAEA standards and inter-run variation around the expected value $\mathrm{S} 1 \pm 0.45 \%$, S2 $\pm 0.72 \%$, S3 $\pm 0.13 \%$, $\mathrm{S} 4 \pm 1.07 \%$, SO6 $\pm 0.71 \%$, NBS $127 \pm 0.21 \%$ ) and 8 internal standards. 

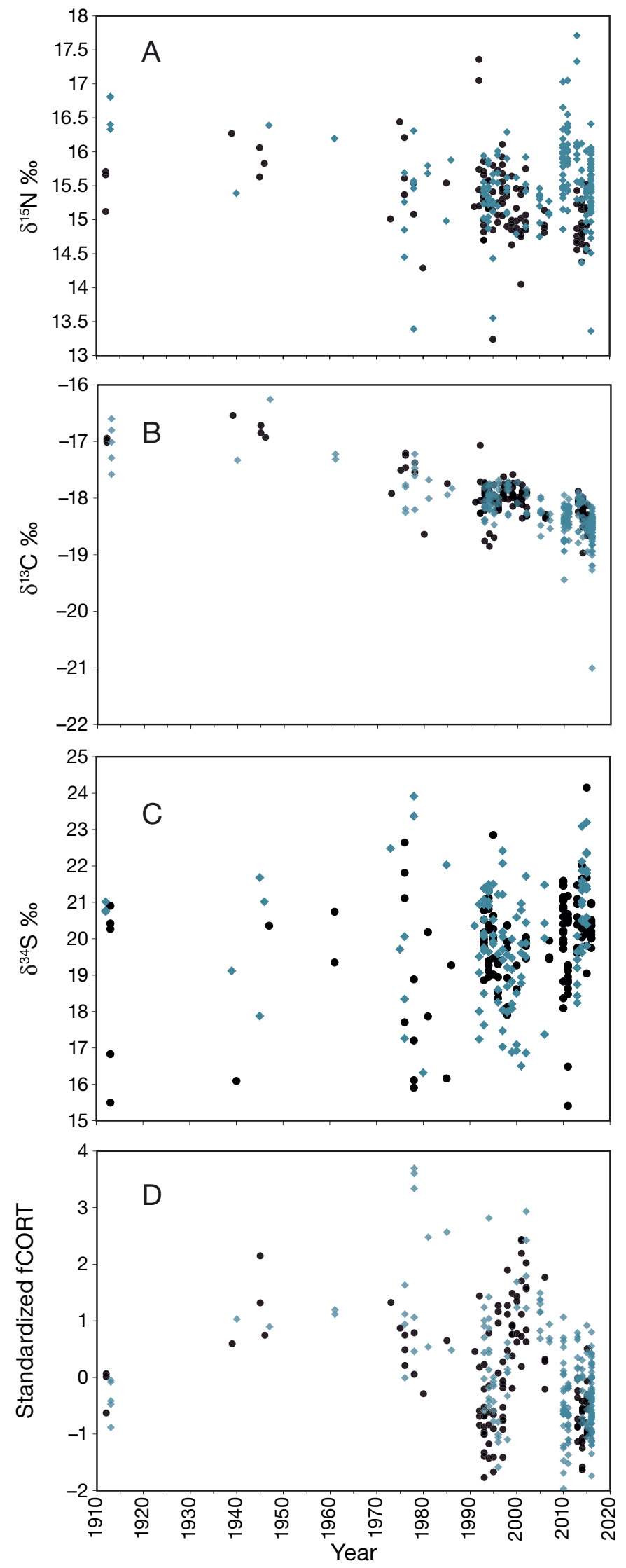

\section{Environmental variables}

To detect course-grained patterns in the responses of red-legged kittiwake isotopic signatures and physiology (Fig. 2) to long-term environmental variability, we used regional climate indices that have been shown to be ecologically relevant and/or detect regime shifts. Environmental predictors (www.beringclimate.noaa.gov/data/index.php) were selected based on 2 criteria: (1) ecological relevance, and (2) a correlation between -0.5 and 0.5 with any of the other candidate variables. April sea-ice coverage was the one exception, which is correlated $(-0.76)$ with the annual Pacific Decadal Oscillation (PDO) index (Mantua \& Hare 2002). We retained April sea-ice coverage in our models due to the potential ecological impacts of ice cover on the return migration to the colony at the risk of affecting the explanatory power of the PDO in our models. Variables included in models of head feather parameters included Year, PDO, the Arctic Oscillation (AO), and February sea-ice coverage (IceFeb), and for primary feathers, Year, PDO, the AO, the Aleutian Low (ALow), and April sea-ice coverage (IceApr). Detailed descriptions follow.

We included Year in the model selection process to account for any trends over time not fully captured by the other parameters (Bond et al. 2003). In the case of carbon, Year accounted for the Suess effect (Revelle \& Suess 1957).

The PDO has historically been the primary indicator of regime shifts in the Bering Sea (Rodionov \& Overland 2005), and previously has been related to seabird physiology and diets on the Pribilof Islands (Satterthwaite et al. 2012). The PDO is derived from a principal component analysis of sea surface temperature anomalies across the North Pacific (above $20^{\circ} \mathrm{N}$ latitude). It is corrected for the global average temperature, so is independent of warming trends associated with climate change (Newman et al. 2016). Positive PDO values are associated with generally warmer conditions (e.g. low winter sea-ice extent and early spring retreat in the Bering Sea), while

Fig. 2. Red-legged kittiwake stable isotope signatures and stress exposure from 1913 to 2016. (A) $\delta^{15} \mathrm{~N}$ values for head feathers (blue diamonds, $\mathrm{n}=194$ individuals) and first primary feathers (black circles, $\mathrm{n}=122$ individuals). (B) $\delta^{13} \mathrm{C}$ values for head and first primary feathers. (C) $\delta^{34} \mathrm{~S}$ values for head and first primary feathers. (D) Standardized fCORT concentration for head and first primary feathers. Concentrations have been standardized ((concentration-mean concentration)/SD) to illustrate temporal trends and avoid comparing concentrations between feather types 
negative values are associated with generally colder conditions.

In the past few decades, the AO has manifested regime shifts more prominently than the PDO (Rodionov \& Overland 2005). The AO is derived from an empirical orthogonal function of monthly mean sealevel pressures poleward of $20^{\circ} \mathrm{N}$ (Thompson \& Wallace 1998). The formation, retention, and movement of sea ice are highly influenced by the AO (Rigor et al. 2002).

Another winter index that potentially predicts the productivity of the Bering Sea is the ALow (i.e. the winter North Pacific Index). The ALow is the mean area-weighted sea-level pressure in November to March, expressed as anomalies compared with the period 1961-2000. The position and strength of the ALow is hypothesized to affect the degree and depth to which the surface layers are mixed, which influences the nutrients available to organisms during spring and summer plankton production (Rodionov \& Overland 2005, Rodionov et al. 2007).

Previous research has suggested that red-legged kittiwake migration might be influenced by sea ice (Orben et al. 2015), and indicates that sea ice during the month of April affects breeding season conditions and reproduction (Murphy et al. 2016). We used seaice coverage in February and April as explanatory variables in our head and primary feather models, respectively. We calculated ice coverage from maps produced by the National Atmospheric and Oceanic Administration (ftp://sidads.colorado.edu/DATASETS/ NOAA/G02135/, available from the National Snow and Ice Data Center). We converted images to grayscale in Adobe Photoshop then calculated the mean pixel intensity in Image $\mathrm{J}$ as a proxy for ice coverage. Based on recent records of red-legged kittiwake winter migration patterns, we estimated sea-ice coverage for an area including the Bering Sea, Sea of Okhotsk, and a small portion of the North Pacific (Orben et al. 2018).

\section{Statistical analysis}

We conducted all analyses in $\mathrm{R}$ version 3.2 .3 ( $\mathrm{R}$ Core Development Team 2015). Head feather corticosterone (fCORT) concentrations were calculated by feather length $\left(\mathrm{pg} \mathrm{mm}{ }^{-1}\right.$, detrended for the effect of sample mass, Will et al. 2014), and primary fCORT concentrations were calculated by feather sample mass (ng g ${ }^{-1}$ ). All fCORT concentrations were logtransformed to meet assumptions of normality. We show standardized fCORT concentrations in all fig- ures, calculated as the difference of the concentration from the mean divided by the standard deviation. Stable isotope signatures obtained from both head and primary feathers were normally distributed. We normalized and centered the Year and Ice Coverage explanatory variables so as not to overinflate the coefficient estimates.

We ran multiple general linear mixed-effects models using the 'Ime4' package in R (Bates et al. 2015). Models included fCORT, $\delta^{15} \mathrm{~N}, \delta^{13} \mathrm{C}$, or $\delta^{34} \mathrm{~S}$ as response variables, Year as a random intercept and the aforementioned environmental variables as fixed effects. We used Akaike's information criterion (AIC) model selection, based on corrected AIC $\left(\mathrm{AIC}_{\mathrm{C}}\right)$ for small sample sizes, to address whether stable isotope signatures and nutritional stress changed in response to changes in the environment. We report the averaged model from the $95 \%$ model subset (the model set whose cumulative model weight is 0.95) and the summed variable model weights. The averaged model coefficients were calculated as $\bar{\beta}=\sum_{i=1}^{n} W_{i} \hat{\beta}$ where the model-averaged parameter estimate $(\bar{\beta})$ is the summation of the model weight $\left(w_{\mathrm{i}}\right)$ and estimated model coefficient $(\hat{\beta})$ for each model in the subset ( $n=$ total number of models) (Symonds \& Moussalli 2011, refer to Tables S3 \& S4 in the Supplement for complete model sets). We modeled response variables at 2 timescales to accommodate the temporal limitations of some of our explanatory variables and the sparse data points from early years: 1913-present (hereafter the 'all data' dataset), and 1979-present (the '40-yr' dataset). The all data were tested against the PDO, ALow (primaries only), ice cover, and Year while the 40-yr data were tested against the PDO, ALow (primaries only), Year, AO, and ice cover.

We also used linear regression analysis (' $\mathrm{lm}$ ' function in R) to test whether nutritional stress and/or stable isotope values of an individual during one season were correlated with stress and stable isotope signatures in that same individual the following season. Using the 'rptR' package in R (repeatability analysis; Stoffel et al. 2017) we also tested for interseasonal individual consistency in stable isotope signatures and nutritional stress. Finally, we used population data reported by the United States Fish and Wildlife Service's Alaska Maritime National Wildlife Refuge to examine possible relationships between winter physiology or stable isotope signatures and population size. The red-legged kittiwake population on St. George Island experienced a strong decline in the years 1976 to 1989, and has since been increasing (up to the last reported count in 2014, Tappa \& Romano 
Table 1. Head feather AIC model selection results. Averaged models for fCORT, $\delta^{13} \mathrm{C}, \delta^{14} \mathrm{~N}$, and $\delta^{34} \mathrm{~S}$ are described for the full dataset ('All data', upper row) and the $40 \mathrm{yr}$ dataset ('40 yr', lower row). The number of models in the $95 \%$ model subset is noted in the first column and also given are the summed model weights, $\Sigma w_{i}$, where $w_{i}$ is the probability of model $i$ being the best model in the subset, and $w_{i}$ is summed for each model containing the variable of interest (PDO [Pacific Decadal Oscillation]; Year; IceFeb [February sea-ice coverage]; AO [Arctic Oscillation]). For the full set of candidate models refer to the Supplement at www.int-res.com/articles/suppl/m593p261_supp.pdf

\begin{tabular}{|c|c|c|c|c|c|}
\hline \multirow{2}{*}{$\begin{array}{l}\text { Models } \\
\text { in subset }\end{array}$} & \multirow{2}{*}{$\begin{array}{l}\text { Averaged model head feathers } \\
\text { Variable }=\beta_{\text {intercept }}+\beta_{\mathrm{PDO}}+\beta_{\text {Year }}+\beta_{\mathrm{IceFeb}}+\beta_{\mathrm{AO}}\end{array}$} & \multicolumn{4}{|c|}{$-\Sigma W_{i}$} \\
\hline & & PDO & Year & IceFeb & $\mathrm{AO}$ \\
\hline \multicolumn{6}{|l|}{ fCORT } \\
\hline 3 & $\mathrm{fCORT}_{\text {All data }}=0.35-0.012(\mathrm{PDO})-0.001($ Year $)$ & 0.53 & 0.69 & - & - \\
\hline 9 & $\mathrm{fCORT}_{40 \mathrm{yr}}=0.278-0.005(\mathrm{PDO})-0.001($ Year $)+0.005($ IceFeb $)+0.012(\mathrm{AO})$ & 0.51 & 0.62 & 0.45 & 0.32 \\
\hline \multicolumn{6}{|l|}{$\delta^{13} \mathbf{C}$} \\
\hline 2 & $\delta^{13} \mathrm{C}_{\text {All data }}=-18.31-0.04(\mathrm{PDO})-0.016$ (Year) & 0.61 & 1 & - & - \\
\hline 4 & $\delta^{13} C_{40 \text { yr }}=-17.98-0.049(\mathrm{PDO})-0.02($ Year $)-0.002($ IceFeb $)+0.007(\mathrm{AO})$ & 0.36 & 0.78 & 0.2 & 0.18 \\
\hline \multicolumn{6}{|l|}{$\delta^{15} \mathbf{N}$} \\
\hline 3 & $\delta^{15} \mathrm{~N}_{\text {All data }}=15.65-0.08(\mathrm{PDO})-0.006($ Year $)$ & 0.59 & 0.88 & - & - \\
\hline 7 & $\delta^{15} \mathrm{~N}_{40 \mathrm{yr}}=14.93-0.05(\mathrm{PDO})+0.002($ Year $)+0.002($ IceFeb $)-0.13(\mathrm{AO})$ & 0.56 & 0.23 & 0.16 & 0.9 \\
\hline \multicolumn{6}{|c|}{ 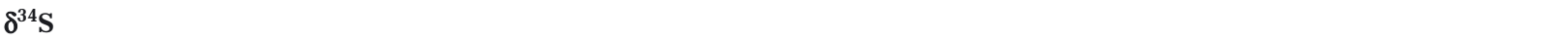 } \\
\hline 2 & $\delta^{34} \mathrm{~S}_{\text {All data }}=18.94+0.018(\mathrm{PDO})+0.019($ Year $)$ & 0.25 & 0.95 & - & - \\
\hline 5 & $\delta^{34} \mathrm{~S}_{40 \mathrm{yr}}=19.47+0.17(\mathrm{PDO})+0.045($ Year $)+0.011(\mathrm{IceFeb})+0.006(\mathrm{AO})$ & 0.69 & 0.97 & 0.27 & 0.12 \\
\hline
\end{tabular}

2017, Fig. S1 in the Supplement). We used a nonparametric bootstrapping test for small sample sizes (Dwivedi et al. 2017) to compare the mean stable isotope values and fCORT concentrations in head feathers between the time periods 1976-1989 and 1990-2014.

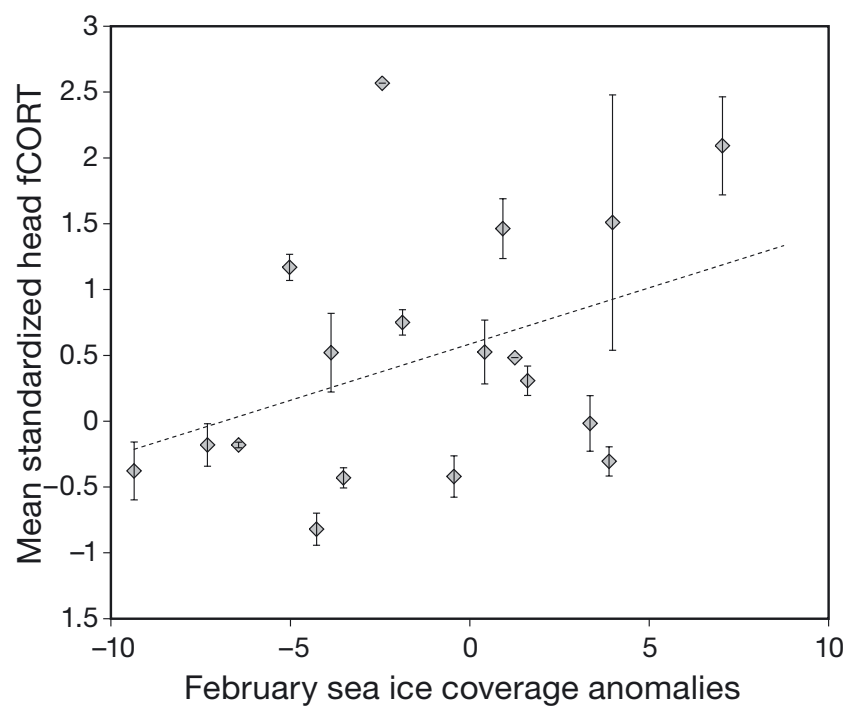

Fig. 3. Exposure of red-legged kittiwake to stress during the winter (as revealed by head fCORT concentrations) in response to February sea-ice coverage. The average of annual standardized head fCORT concentrations are shown $\pm \mathrm{SE}, \mathrm{n}=$ $18 \mathrm{yr}$; dashed line represents the slope of the linear regression $\left(\mathrm{r}^{2}=0.19\right.$, mixed effects model, with year as a random effect:

$$
F_{1,13}=4.36, \mathrm{p}=0.056 \text { ) }
$$

\section{RESULTS}

\section{Temporal dynamics of late winter stable isotopes and nutritional stress as reflected in head feathers}

Sea-ice coverage was positively correlated with fCORT concentrations (Table 1, Fig. 3). At the century scale, fCORT concentrations have generally declined over time and were lower in years when the PDO was positive (Table 1).

In general, Year best predicted changes in wintertime $\delta^{15} \mathrm{~N}, \delta^{13} \mathrm{C}$, and $\delta^{34} \mathrm{~S}$ over the past century (Table 1). $\delta^{13} \mathrm{C}$ values declined over time (Suess effect); however, $\delta^{34} \mathrm{~S}$ values increased over time and increased in years with positive PDO values (Table 1). The AO appeared most frequently in the $95 \%$ model subset for $\delta^{15} \mathrm{~N}$ values and $\delta^{15} \mathrm{~N}$ values decreased during positive phases of the AO (Table 1). In the past $40 \mathrm{yr}, \delta^{15} \mathrm{~N}$ values have generally increased; however, over the longer time period covered by all of the data, $\delta^{15} \mathrm{~N}$ values have decreased (Table 1).

\section{Temporal dynamics of breeding season stable isotopes and nutritional stress as reflected in primary feathers}

During the breeding season, fCORT concentrations decreased when the ALow and PDO were positive. $\delta^{13} \mathrm{C}$ values decreased during positive phases of the 
Table 2. Primary feather AIC model selection results. Averaged models for fCORT, $\delta^{13} \mathrm{C}, \delta^{14} \mathrm{~N}$, and $\delta^{34} \mathrm{~S}$ are described for the full dataset ('All data', upper row) and the $40 \mathrm{yr}$ dataset ('40 yr', lower row). The number of models in the $95 \%$ model subset is noted in the first column and also given are the summed model weights, $\Sigma W_{i}$, where $W_{i}$ is the probability of model $i$ being the best model in the subset and $W_{i}$ is summed for each model containing the explanatory variables (ALow [Aleutian Low]; PDO [Pacific Decadal Oscillation]; Year; IceApr [April sea-ice coverage]; AO [Arctic Oscillation]). For the full set of candidate models refer to the Supplement

\begin{tabular}{|c|c|c|c|c|c|c|}
\hline $\begin{array}{l}\text { Models } \\
\text { in subset }\end{array}$ & $\begin{array}{c}\text { Averaged model primary feathers } \\
\text { Variable }=\beta_{\text {intercept }}+\beta_{\text {ALow }}+\beta_{\mathrm{PDO}}+\beta_{\text {Year }}+\beta_{\text {IceApr }}+\beta_{\mathrm{AO}}\end{array}$ & ALow & \multicolumn{3}{|c|}{$-\Sigma W_{i}$} & $\mathrm{AO}$ \\
\hline \multicolumn{7}{|c|}{ fCORT } \\
\hline 12 & fCORT $_{40 \mathrm{yr}}=0.96-0.116($ ALow $)-0.151(\mathrm{PDO})-0.001($ Year $)-0.003($ IceApr $)-0.005(\mathrm{AO})$ & 0.85 & 0.96 & 0.33 & 0.27 & 0.35 \\
\hline \multicolumn{7}{|c|}{$\delta^{13} \mathrm{C}$} \\
\hline \multicolumn{7}{|c|}{$\delta^{15} \mathbf{N}$} \\
\hline 4 & $\delta^{15} \mathrm{~N}_{\text {All data }}=-15.04-0.02(\mathrm{ALow})+0.021(\mathrm{PDO})-0.01(\mathrm{Year})$ & 0.3 & 0.31 & 0.99 & - & - \\
\hline 20 & $\delta^{15} \mathrm{~N}_{40 \mathrm{yr}}=-14.77-0.05(\mathrm{ALow})-0.008(\mathrm{PDO})-0.02($ Year $)-0.03(\mathrm{IceApr})+0.02(\mathrm{AO})$ & 0.42 & 0.27 & 0.88 & 0.8 & 0.29 \\
\hline \multicolumn{7}{|c|}{$\delta^{34} \mathbf{S}$} \\
\hline
\end{tabular}

PDO, whereas $\delta^{15} \mathrm{~N}$ and $\delta^{34} \mathrm{~S}$ values increased when the PDO was positive (Table 2).

In the past $40 \mathrm{yr}, \delta^{13} \mathrm{C}$ and $\delta^{15} \mathrm{~N}$ decreased over time (Table 2). The PDO was most often included in the top models that described recent changes in $\delta^{34} \mathrm{~S}$ values (Table 2). During warm conditions (positive PDO), fCORT concentrations decreased (Fig. 4), and $\delta^{34} \mathrm{~S}$ values increased (Table 2). When April sea-ice coverage was low, $\delta^{15} \mathrm{~N}$ values increased (Table 2 ).

The relationship between $\delta^{15} \mathrm{~N}$ and the PDO reversed between the 2 model sets. In the past $40 \mathrm{yr}$, $\delta^{15} \mathrm{~N}$ values decreased during warm conditions (positive PDO) compared with having increased during warm conditions when all of the data were considered (Table 2).

\section{Inter-seasonal relationships}

Elevated stress levels in primary feathers $(\mathrm{n}=69)$, grown during the breeding season, corresponded to elevated stress levels in head feathers, grown during the winter $\left(F_{1,67}=17.26, \mathrm{p}<0.0001\right.$, Fig. 5$) . \delta^{13} \mathrm{C}$ values were positively correlated between the breeding and wintering seasons $\left(F_{1,67}=43.12, \mathrm{p}<0.0001\right.$, Fig. 5). There was no correlation in $\delta^{15} \mathrm{~N}$ or $\delta^{34} \mathrm{~S}$ signatures between the breeding season and the following winter $\left(\delta^{15} \mathrm{~N}, F_{1,67}=1.675, \mathrm{p}=0.2 ; \delta^{34} \mathrm{~S}, F_{1,62}=\right.$ $0.3451, \mathrm{p}=0.56)$. There was low consistency among the stable isotope signatures and nutritional stress of individuals $\left(\delta^{15} \mathrm{~N}\right.$, repeatability estimate $R=0.122$; $\delta^{13} \mathrm{C}, R=0.077 ; \delta^{34} \mathrm{~S}, R=0.019$; fCORT, $R=0$ ) but high consistency within a given year $\left(\delta^{15} \mathrm{~N}, R=0.412\right.$; $\delta^{13} \mathrm{C}, R=0.686 ; \delta^{34} \mathrm{~S}, R=0.433$; fCORT, $\left.R=0.436\right)$.

Seven of the museum specimens collected late in the breeding season had already grown new first primary feathers, enabling us to test whether head feather stress and stable isotope values were correlated between the winter period and the following summer period. Nutritional stress, $\delta^{15} \mathrm{~N}$ and $\delta^{13} \mathrm{C}$ val-

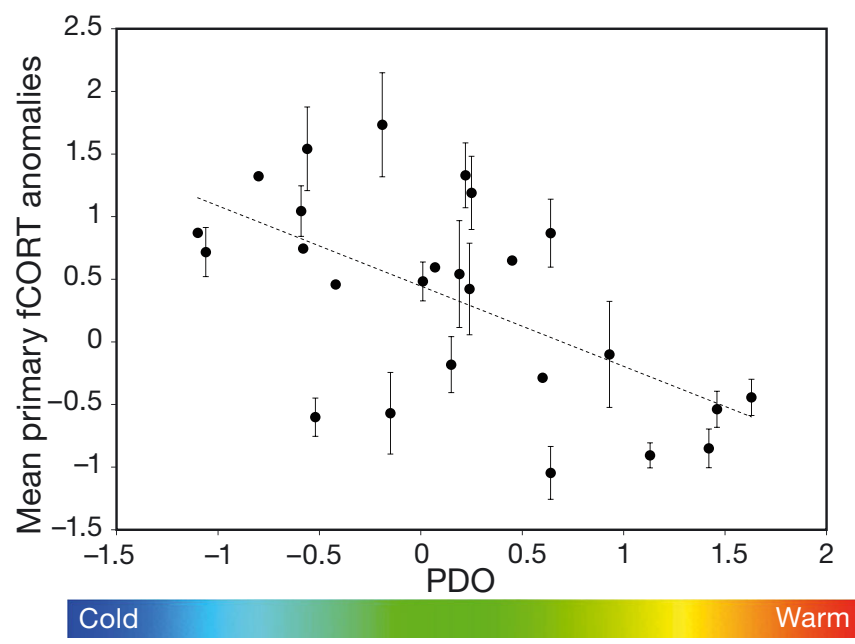

Fig. 4. Summer stress in red-legged kittiwakes (as reflected in primary fCORT concentrations) was inversely related to PDO. Annual primary fCORT standardized means $\pm \mathrm{SE}, \mathrm{n}=$ $27 \mathrm{yr}$; line represents the slope of the linear regression $\left(\mathrm{r}^{2}=\right.$ 0.36 , mixed effects model with year as a random factor:

$$
F_{1,23}=12.08, \mathrm{p}=0.002 \text { ) }
$$



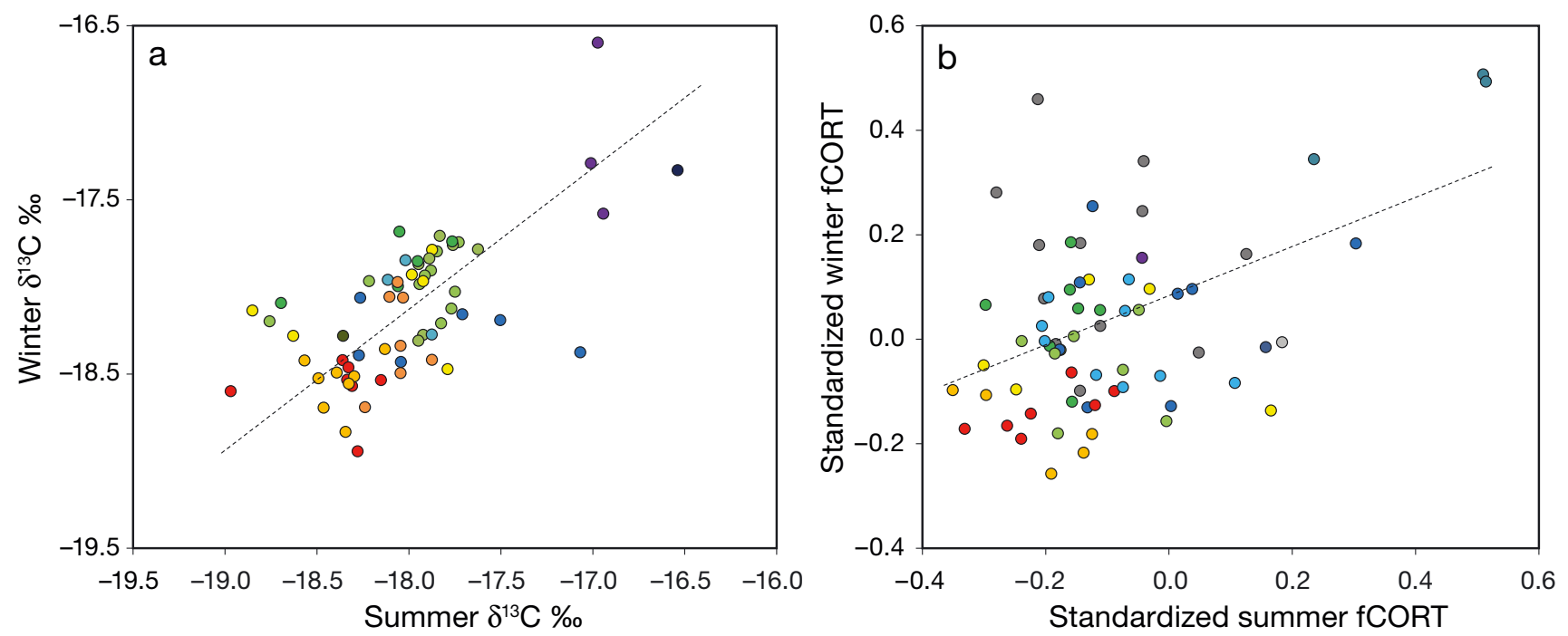

Fig. 5. Individual red-legged kittiwake summer and winter $\delta^{13} \mathrm{C}$ values (a) and stress levels (b). $\delta^{13} \mathrm{C}$ values and head and primary fCORT concentrations for feathers from 69 individuals from 15 different years between 1913 and 2016 (colored by year for illustrative purposes); dashed line represents the slope of the linear regression (fCORT: $\mathrm{r}^{2}=0.20, F_{1,67}=17.26, \mathrm{p}<0.0001$; $\left.\delta^{13} \mathrm{C}: \mathrm{r}^{2}=0.41, F_{1,67}=43.12, \mathrm{p}<0.0001\right)$

ues during the pre-nuptial molt did not correlate with nutritional stress, $\delta^{15} \mathrm{~N}$ and $\delta^{13} \mathrm{C}$ values during the breeding season $\left(F_{1,6}<0.733, \mathrm{p}>0.425\right.$ for simple linear regressions on $\delta^{15} \mathrm{~N}, \delta^{13} \mathrm{C}$, and fCORT, with values for head feathers as the predictor and values for primaries as the response). Head feather $\delta^{34} \mathrm{~S}$ values tended to be inversely correlated with $\delta^{34} \mathrm{~S}$ values in primary feathers $\left(F_{1,6}=4.018, \mathrm{p}=0.092\right)$.

\section{Physiology and population trends}

Head fCORT concentrations were higher $(0.55 \mathrm{pg}$ $\mathrm{mm}^{-1} \pm 0.06$ ) during the period of red-legged kittiwake population decline compared with the period of population increase $\left(0.28 \mathrm{pg} \mathrm{mm} \mathrm{m}^{-1} \pm 0.01 ; t_{123}=\right.$ 4.51, $\mathrm{p}<0.0001) . \delta^{13} \mathrm{C}$ values in head feathers from 1976 to 1989 (mean \pm SE: $-17.80 \% \pm 0.09$ ) were higher than those from 1990 to $2014(-18.23 \% \pm 0.03$; $\left.t_{123}=4.62, \mathrm{p}<0.0001\right)$, while $\delta^{34} \mathrm{~S}$ values were lower (18.44\% \pm 0.68$)$ in the period 1976-1989 compared with $1990-2014\left(19.95 \% \pm 0.11 ; t_{113}=-2.19, \mathrm{p}=\right.$ 0.018). There was a tendency for $\delta^{15} \mathrm{~N}$ to be higher after $1989(15.30 \%$ \% \pm 0.21 compared with $15.62 \%$ o $\left.0.05 ; t_{123}=-1.53, \mathrm{p}=0.08\right)$.

\section{DISCUSSION}

In long-lived species, such as red-legged kittiwakes, examining the response of individuals to environmental variability may reveal more clearly how changes in climate influences the habitat use and nutritional status of a species. Connections can then be made from the individual to parameters that affect individual fitness and population processes (Satterthwaite et al. 2012), such as adult quality, survival, and breeding attempts. We found that redlegged kittiwakes experienced food shortages during cold winters when sea ice-coverage was high and that both stress and stable isotope data indicate that the changes red-legged kittiwakes have experienced in previous decades were gradual and associated with changes in ocean temperature (the PDO). We also present preliminary evidence that these responses may correspond to the population trajectory of red-legged kittiwakes.

During the breeding season, red-legged kittiwakes rely on myctophids, primarily Stenobrachius leucopserus (Byrd \& Williams 1993), the most abundant myctophid species in the Bering Sea (Beamish et al. 1999). Myctophids are mesopelagic fish that follow their prey in a diel vertical migration, rising to the upper water column at night (Beamish et al. 1999), where they become available to nocturnally foraging red-legged kittiwakes (Storer 1987). We found that, during positive phases of the PDO, red-legged kittiwake stable isotope signatures appear to consist of more oceanic prey species (lower $\delta^{13} \mathrm{C}$, and increased $\left.\delta^{34} \mathrm{~S}\right)$. Concurrently, birds had lower levels of nutritional stress, as evidenced by low fCORT concentrations, suggesting that food may have been abundant during these periods. Specific mechanisms of how warm conditions might enhance myctophid abun- 
dance and/or availability, which would translate into low nutritional stress incurred by birds, are not known. One possibility is that the upper mixed layer is shallower in these years due to lighter winds (a weak ALow), and myctophids are easier to catch. Another possibility is that red-legged kittiwakes make use of the eddy field (Paredes et al. 2014, Yamamoto et al. 2016) located to the south of the Pribilof Islands (Napp et al. 2000). Eddy strength is positively correlated with the PDO (Panteleev et al. 2012). Further investigation into what drives myctophid abundance and makes them available to kittiwakes (especially during the day) is needed to clarify how warm conditions might reduce nutritional stress in breeding red-legged kittiwakes.

In contrast to the breeding period, it is unknown what red-legged kittiwakes eat during the winter. This makes it difficult to interpret the patterns we observed during the non-breeding period. Winters with high sea-ice coverage were associated with higher fCORT concentrations and higher $\delta^{15} \mathrm{~N}$ values. This suggests that birds were food limited and may have had to rely more heavily on endogenous reserves to meet their energy demands (Cherel et al. 2005). The mechanistic relationship between red-legged kittiwakes and winter sea ice, however, is unclear. Orben et al. (2015) suggested that the foraging of redlegged kittiwakes may be ice associated in a singleyear study, but then found no consistent pattern of ice-habitat use in subsequent multi-year investigations (Orben et al. 2018). It is possible that red-legged kittiwakes may consume hyperid amphipods such as Themisto spp. (Byrd \& Williams 1993) during the winter. Hyperids are predatory amphipods that are associated with the cold waters of the northern Bering Sea (Pinchuk et al. 2013) and have high $\delta^{15} \mathrm{~N}$ values relative to other zooplankton (Gorbatenko et al. 2014). However, fCORT concentrations suggest that too much ice may not be ideal; a signal that holds when head fCORT values, including those prior to 1979, were compared with reconstructed winter seaice coverage for the entire Arctic (Fig. S2 in the Supplement). Sea ice may directly interfere with the ability of red-legged kittiwakes to find enough food by acting as a physical barrier, or may dampen the strength of upwelling or eddy features. Alternatively, heavy sea ice in the Bering Sea may be a by-product of strong winds (Wang et al. 2009), which may increase flight (e.g. Amélineau et al. 2014) and/or thermoregulatory (Chappell et al. 1989) costs of overwintering red-legged kittiwakes. We found some evidence for a positive correlation between average continuous wind speed in February and head fCORT concentrations (Fig. S3 in the Supplement). This observation, however, warrants further investigation as the relationship depicted is parabolic and is based on a small sample size $(\mathrm{n}=7 \mathrm{yr})$.

Environmental conditions during the breeding and non-breeding periods, when kittiwakes are in the eastern and western Bering Sea, respectively, appear to be correlated. The response of individuals within a year are similar between the 2 seasons; individuals with high primary (summer) fCORT concentrations had high head (winter) fCORT concentrations (Fig. 5). Circulating levels of corticosterone and the ability of birds to mount a response to prolonged stress change in response to both environmental stressors and the demands of different life stages (Sapolsky et al. 2000). The adrenocortical function in kittiwakes is responsive to environmental variability regardless of life stage and can change rapidly, responding to new stress within a matter of days and recovering from natural food shortages within several weeks (Shultz \& Kitaysky 2008, Kitaysky et al. 2010). In red-legged kittiwakes, 7 mo separate the growth of the first primary feather and new head feathers. Thus, we suggest that the correlation of summer and winter stress is a reflection of environmental conditions that persist throughout the year rather than a carry-over effect. This is supported by high intra-annual consistency, and a positive correlation between $\delta^{13} \mathrm{C}$ values in feathers (which have been shown to be unaffected by fasting, Hertz et al. 2015) grown during the breeding and wintering periods (Fig. 5), suggesting that primary production at the breeding and wintering locations is affected by similar processes within a given year.

Long-term changes in stable isotope values may reflect changes in primary production $\left(\right.$ e.g. $\delta^{13} \mathrm{C}$, Schell 2000) or food web structure (e.g. $\delta^{15} \mathrm{~N}$, Grecian et al. 2016). While $\delta^{15} \mathrm{~N}$ values in both head and primary feathers decreased across our entire dataset, the decline was slight $(\sim 1 \%)$. This is unlikely to indicate changes in trophic organization of the Bering Sea food web since $\sim 3.4 \%$ generally separates a full trophic level (Minagawa \& Wada 1984). More plausible explanations for this decline are long-term changes in baseline $\delta^{15} \mathrm{~N}$ ratios (Cabana \& Rasmussen 1994) or a decline in prey quality over time (Oelbermann \& Scheu 2002). A temporal decline in $\delta^{13} \mathrm{C}$ values in head and primary feathers was much more apparent, but is mostly accounted for when corrected for the Seuss effect (Eide et al. 2017). Since correction factors for the Suess effect vary globally (Gruber et al. 1999), we also analyzed samples for $\delta^{34} \mathrm{~S}$ values to evaluate whether some of the decline 
in $\delta^{13} \mathrm{C}$ may be attributed to a decline in the carrying capacity of the Bering Sea (Schell 2000, 2001). The temporal increase in $\delta^{34} \mathrm{~S}$ values in head feathers and the increase in $\delta^{34} \mathrm{~S}$ values in primary feathers with PDO suggest that changes in primary production have been relatively minor ( $2 \%$, less than the $5 \%$ difference in experimental studies, Connolly et al. 2004). Fur seal Callorhinus ursinus teeth from St. Paul Island (60 km north of St. George Island) also show no evidence for major changes in primary production in the same region between 1948 and 2000 (Newsome et al. 2007). Thus, higher $\delta^{34} \mathrm{~S}$ values may alternatively be interpreted as increased consumption of prey that obtains more nutrients from deep ocean water (Peterson \& Fry 1987).

We did find that the relationship between the food web and climate indices has changed. $\delta^{15} \mathrm{~N}$ values in primary feathers were negatively correlated with the PDO values when considering just the recent $40 \mathrm{yr}$ dataset. However, over the entire dataset, the relationship is positive. The relationship between $\delta^{15} \mathrm{~N}$ values in head feathers and year also changed between the models for these 2 time periods. Schmidt et al. (2015) found that, starting in 2007-2008, Brandt's cormorants breeding in California broke with a previously established 40 yr pattern where El Niño and sea surface temperatures predicted survival and reproduction. It is possible that red-legged kittiwakes reflect recent (within the last 4 decades) changes in ecosystem responses to oceanographic conditions, which result in changes in the relationship between climate indices, stable isotope signatures, and nutritional stress. Our results suggest that this may have occurred in the past, and it may be expected to occur again in response to climate regime shifts.

Our study provides some support for the hypothesis that conditions during the winter may negatively affect red-legged kittiwakes. We provide evidence that, in the years covered by this study, colder conditions and higher sea-ice coverage during the winter may correspond to increased levels of stress incurred by birds. These conditions likely led to food shortages (Sorenson et al. 2017), a conclusion supported by a concurrent increase in $\delta^{15} \mathrm{~N}$. We acknowledge that it is possible that parasite (Raouf et al. 2006) or contaminant loads (Strong et al. 2015) may also contribute to higher stress during adverse winter conditions; however, little is known with respect to how these stressors might contribute to adult physiology and behavior during the non-breeding period. The mechanistic link between corticosterone and fitness has proven complex (e.g. Goutte et al. 2010, Madliger \& Love 2016), but in black-legged kittiwakes
Rissa tridactyla, higher nutritional stress incurred during reproduction has been shown to correlate with an increased probability of mortality (Satterthwaite et al. 2010). Elevated levels of nutritional stress and more on-shelf foraging in food webs with less benthic water inputs characterized red-legged kittiwake's overwinter experience during a period of population decrease (1976-1989). These findings are preliminary and are based on a very small sample size. However, for black-legged kittiwakes, time spent on the wintering grounds was correlated with the ability of individuals to recover from molecular damage that occurred during the breeding season (Schultner et al. 2014). This suggests that the overwinter period plays an important role in repair and maintenance at the cellular level. To substantiate this hypothesized link between red-legged kittiwake physiological status during winter molt and survival to the next life stage or skipping reproduction (as both affect adult annual return rates), the relationship between fCORT concentrations and red-legged kittiwake survival needs to be investigated on an individual basis (e.g. as done for black-legged kittiwakes, Satterthwaite et al. 2010). Furthermore, to understand the response of red-legged kittiwakes to future changes in the Bering Sea climate, we must improve our understanding of the migratory patterns of this species, their diets during the non-breeding season, and myctophid ecology to understand how changes in the region's environment affects food availability for this species.

Acknowledgements. We thank the museum curators and field crews that helped to populate our feather library. These include, but are not limited to: Kimball Garrett, Andrew B. Johnson, Dean Kildaw, Nobuo Kokubun, Rachael Orben, Steve Rogers, Gary Shugart, Alan Springer, Philip Unitt, Jack Withrow, Chris Witt (listed alphabetically). A big thank you to Tim Howe and Norma Haubenstock at the Alaska Stable Isotope Facility. Thank you also to G. Breed, G. Hunt Jr., R. Orben, A. Powell, A. Springer, and 3 anonymous reviewers whose thoughtful comments gave this manuscript depth and direction. All samples obtained from live birds were done so with the approval of the University of Alaska Fairbanks' Institutional Animal Care and Use Committee, and under A. Kitaysky's Federal and State collection permits. This project was made possible by the North Pacific Research Board (project \# 1410), and is publication \# 662.

\section{LITERATURE CITED}

Alverson DL (1992) A review of commercial fisheries and the Steller sea lion (Eumetopias jubatus): the conflict arena. Rev Aquat Sci 6:203-256

Amélineau F, Péron C, Lescroël A, Authier M, Provost P, Grémillet D (2014) Windscape and tortuosity shape the 
flight costs of northern gannets. J Exp Biol 217:876-885

Anonymous (1993) Is it food? Addressing marine mammal and seabird declines, workshop summary. Alaska Sea Grant Report 93-1. University of Alaska Fairbanks, Fairbanks, AK

Bates D, Maechler M, Bolker B, Walker S (2014) Fitting linear mixed-effects models using lme4. J Statist Software 67:1-48

Beamish RJ, Leask KD, Orlov AM, Ivanov OA, Sinclaire B, Balanov AA (1999) The ecology, distribution, and abundance of midwater fishes of the Subarctic Pacific gyres. Prog Oceanogr 43:399-442

Bond NA, Overland JE, Spillane M, Stabeno P (2003) Recent shifts in the state of the North Pacific. Geophys Res Lett 30:2183

Bortolotti GR, Marchant TA, Blas J, German T (2008) Corticosterone in feathers is a long-term, integrated measure of avian stress physiology. Funct Ecol 22:494-500

Bortolotti GR, Marchant T, Blas J, Cabezas S (2009) Tracking stress: localisation, deposition and stability of corticosterone in feathers. J Exp Biol 212:1477-1482

Byrd GV, Williams JC (1993) Red-legged Kittiake (Rissa brevirostris). In: Rodewald PG (ed) The birds of North America. Cornell Lab of Ornithology, Ithaca, NY

Cabana G, Rasmussen JB (1994) Modeling food chain structure and contaminant bioaccumulation using stable nitrogen isotopes. Nature 372:255-257

* Chappell MA, Morgan KR, Souza SL, Bucher TL (1989) Convection and thermoregulation in two Antarctic seabirds. J Comp Physiol B 159:313-322

Charapata PM (2016) Back to the future: Pacific walrus stress response and status in a changing Arctic. Master's thesis, University of Alaska Fairbanks

Cherel Y, Hobson KA, Bailleul F, Groscolas R (2005) Nutrition, physiology, and stable isotopes: new information from fasting and molting penguins. Ecology 86:2881-2888

* Cherel Y, Connan M, Jaeger A, Richard P (2014) Seabird year-round and historical feeding ecology: blood and feather $\delta^{13} \mathrm{C}$ and $\delta^{15} \mathrm{~N}$ values document foraging plasticity of small sympatric petrels. Mar Ecol Prog Ser 505: $267-280$

* Connolly RM, Guest MA, Melville AJ, Oakes JM (2004) Sulfur stable isotopes separate producers in marine foodweb analysis. Oecologia 138:161-167

* Dobush GR, Ankney CD, Krementz DG (1985) The effect of apparatus, extraction time, solvent type on lipid extractions of snow geese. Can J Zool 63:1917-1920

W wivedi AK, Mallawaarachchi I, Alvarado LA (2017) Analysis of small sample size studies using nonparametric bootstrap test with pooled resampling method. Statist Med 36:2187-2205

Eide M, Olsen A, Ninnemann US, Eldevik T (2017) A global estimate of the full oceanic ${ }^{13} \mathrm{C}$ Suess effect since the preindustrial. Global Biogeochem Cycles 31:492-514

Fry B (1988) Food web structure on Georges Bank from stable C, N, and S isotopic compositions. Limnol Oceanogr 33:1182-1190

Gabrielson IN, Lincoln FC (1959) The birds of Alaska. Stackpole Co., Harrisburg, PA

* Gorbatenko KM, Lazhentsev AE, Kiyashko SI (2014) Seasonal dynamics of the trophic status of zooplankton in the Sea of Okhotsk (based on data from stable carbon- and nitrogen-isotope analysis). Russ J Mar Biol 40:519-531

Goutte A, Angelier F, Welcker J, Moe B and others (2010) Long-term survival effect of corticosterone manipulation in black-legged kittiwakes. Gen Comp Endocrinol 167: 246-251

* Grebmeier JM, Overland JE, Moore SE, Farley EV and others (2006) A major ecosystem shift in the Northern Bering Sea. Science 311:1461-1464

*Grecian WJ, Taylor GA, Loh G, McGill RAR and others (2016) Contrasting migratory responses of two closely related seabirds to long-term climate change. Mar Ecol Prog Ser 559:231-242

* Gruber N, Keeling CD, Bacastow RB, Guenther PR and others (1999) Spatiotemporal patterns of carbon-13 in the global surface oceans and the oceanic Suess effect. Global Biogeochem Cycles 13:307-335

*Hare SR, Mantua NJ (2000) Empirical evidence for North Pacific regime shifts in 1977 and 1989. Prog Oceanogr 47: 103-145

*Harris CM, Madliger CL, Love OP (2016) Temporal overlap and repeatability of feather corticosterone levels: practical considerations for use as a biomarker. Conserv Physiol 4:cow051

Hertz E, Trudel M, Cox MK, Mazumder A (2015) Effects of fasting and nutritional restriction on the isotopic ratios of nitrogen and carbon: a meta-analysis. Ecol Evol 5: 4829-4839

*Hunt GL Jr, Coyle KO, Eisner LB, Farley EV and others (2011) Climate impacts on eastern Bering Sea foodwebs: a synthesis of new data and an assessment of the Oscillating Control Hypothesis. ICES J Mar Sci 68: 1230-1243

Kitaysky AS, Wingfield JC, Piatt JF (1999) Dynamics of food availability, body condition and physiological stress response in breeding black-legged kittiwakes. Funct Ecol 13:577-584

Kitaysky AS, Kitaiskaia EV, Piatt JF, Wingfield JC (2006) A mechanistic link between chick diet and decline in seabirds? Proc R Soc B 273:445-450

Kitaysky AS, Piatt JF, Wingfield JC (2007) Stress hormones link food availability and population processes in seabirds. Mar Ecol Prog Ser 352:245-258

* Kitaysky AS, Piatt JF, Benowitz-Fredericks ZM, Hatch SA, Shultz MT, Kitaiskaia EV, Wingfield JC (2010) Food availability and population processes: severity of nutritional stress during reproduction predicts survival of long-lived seabirds. Funct Ecol 24:625-637

* Lattin CR, Reed JM, DesRochers DW, Romero LM (2011) Elevated corticosterone in feathers correlates with corticosterone-induced decreased feather quality: a validation study. J Avian Biol 42:247-252

Litzow MA, Mueter FJ (2014) Assessing the ecological importance of climate regime shifts: an approach from the North Pacific Ocean. Prog Oceanogr 120:110-119

Madliger CL, Love OP (2016) Conservation implications of a lack of relationship between baseline glucocorticoids and fitness in a wild passerine. Ecol Appl 26: 2732 -2745

* Mantua NJ, Hare SR (2002) The Pacific Decadal Oscillation. J Oceanogr 58:35-44

Minagawa M, Wada E (1984) Stepwise enrichment of ${ }^{15} \mathrm{~N}$ along food chains: further evidence and the relation between $\delta^{15} \mathrm{~N}$ and animal age. Geochim Cosmochim Acta 48:1135-1140

Murphy EC, Roseneau DG, Springer AM, Byrd GV (2016) Breeding chronology and productivity of black-legged kittiwakes Rissa tridactyla at Bluff, Alaska, 1975-2008: associations with regional environmental indices and distant colonies. Mar Ornithol 44:183-201 
Napp JM, Kendall AW Jr, Schumacker JD (2000) A synthesis of biological and physical processes affecting the feeding environment of larval walleye pollock (Theragra chalcogramma) in the eastern Bering Sea. Fish Oceanogr 9: 147-162

Newman M, Alexander MA, Ault TR, Cobb KM and others (2016) The Pacific Decadal Oscillation, revisited. J Clim 29:4399-4427

*Newsome SD, Etnier MA, Giffor-Gonzalez D, Phillips DL and others (2007) The shifting baseline of northern fur seal ecology in the northeast Pacific Ocean. Proc Natl Acad Sci USA 104:9709-9714

Oelbermann K, Scheu S (2002) Stable isotope enrichment $\left(\delta^{15} \mathrm{~N}\right.$ and $\left.\delta^{13} \mathrm{C}\right)$ in a generalist predator (Pardosa lugubris, Araneae: Lycosidae): effects of prey quality. Oecologia 130:337-344

* Orben RA, Irons DB, Paredes R, Roby DD, Phillips RA, Shaffer SA (2015) North or south? Niche separation of endemic red-legged kittiwakes and sympatric blacklegged kittiwakes during their non-breeding migrations. J Biogeogr 42:401-412

* Orben RA, Kokubun N, Fleishman AB, Will AP and others (2018) Persistent annual migration patterns of a specialist seabird. Mar Ecol Prog Ser 593:231-245

Panteleev G, Nechaev D, Yaremchuk M, Kukuchi T, Luchin V (2012) Variability of the Bering Sea circulation in the period 1992-2010. J Oceanogr 68:485-496

* Paredes R, Orben RA, Suryan RM, Irons DB and others (2014) Foraging responses of black-legged kittiwakes to prolonged food-shortages around colonies on the Bering Sea Shelf. PLOS ONE 9:e92520

* Peterson BJ, Fry B (1987) Stable isotopes in ecosystem studies. Annu Rev Ecol Syst 18:293-320

Pinchuk AI, Coyle KO, Farley EV, Renner HM (2013) Emergence of the Arctic Themisto libellula (Amphipoda: Hyperiidae) on the southeastern Bering Sea shelf as a result of the recent cooling, and its potential impact on the pelagic food web. ICES J Mar Sci 70:1244-1254

R Core Development Team (2015) R: a language and environment for statistical computing. R Foundation for Statistical Computing, Vienna

Raouf SA, Smith LC, Brown MB, Wingfield JC, Brown CR (2006) Glucocorticoid hormone levels increase with group size and parasite load in cliff swallows. Anim Behav 71 : 39-48

Renner HM, Mueter F, Drummond BA, Warzybok JA, Sinclair EH (2012) Patterns of change in diets of two piscivorous seabird species during 35 years in the Pribilof Islands. Deep Sea Res II 65-70:273-291

* Renner HM, Drummond BA, Benson AM, Paredes R (2014) Reproductive success of kittiwakes and murres in sequential stages of the nesting period: relationships with diet and oceanography. Deep Sea Res II 109:251-265

Revelle R, Suess HE (1957) Carbon dioxide exchange between atmosphere and ocean and the question of an increase of atmospheric $\mathrm{CO}$, during the past decades. Tellus IX:18-27

Rigor IG, Wallace JM, Colony RL (2002) Response of sea ice to the Arctic Oscillation. J Clim 15:2648-2663

Rodionov S, Overland JE (2005) Application of a sequential regime shift detection method to the Bering Sea ecosystem. ICES J Mar Sci 62:328-332

Rodionov SN, Bond NA, Overland JE (2007) The Aleutian Low, storm tracks, and winter climate variability in the Bering Sea. Deep Sea Res II 54:2560-2577
Sapolsky RM, Romero LM, Munck AU (2000) How do glucocorticoids influence stress responses? Integrating permissive, suppressive, stimulatory, and preparative actions. Endocr Rev 21:55-89

Satterthwaite WH, Hatch SA, Piatt JF, Kitaysky AS, Mangel $M$ (2010) Unifying quantitative life-history theory and field endocrinology to assess prudent parenthood in a long-lived seabird. Evol Ecol Res 12:779-792

Satterthwaite WH, Kitaysky AS, Mangel M (2012) Linking climate variability, productivity and stress to demography in a long-lived seabird. Mar Ecol Prog Ser 454: 221-235

Schell DM (2000) Declining carrying capacity in the Bering Sea: isotopic evidence from whale baleen. Limnol Oceanogr 45:459-462

Schell DM (2001) Carbon isotope ratio variations in Bering Sea biota: the role of anthropogenic carbon dioxide. Limnol Oceanogr 46:999-1000

Schell DM, Barnett BA, Vinette KA (1998) Carbon and nitrogen isotope ratios in zooplankton of the Bering, Chukchi and Beaufort seas. Mar Ecol Prog Ser 162:11-23

Schmidt AE, Dybala KE, Botsford LW, Eadie JM, Bradley RW, Jahncke J (2015) Shifting effects of ocean conditions on survival and breeding probability of a long-lived seabird. PLOS ONE 10:e0132372

* Schultner J, Moe B, Chastel O, Bech C, Kitaysky AS (2014) Migration and stress during reproduction govern telomere dynamics in a seabird. Biol Lett 10:20130889

* Shultz MT, Kitaysky AS (2008) Spatial and temporal dynamics of corticosterone and corticosterone binding globulin are driven by environmental heterogeneity. Gen Comp Endocrinol 155:717-728

* Sorenson GH, Dey CJ, Madliger CL, Love OP (2017) Effectiveness of baseline corticosterone as a monitoring tool for fitness: a meta-analysis in seabirds. Oecologia 183: 353-365

* Springer AM (1992) A review: walleye pollock in the North Pacific - how much difference do they really make? Fish Oceanogr 1:80-96

Springer AM (1998) Is it all climate change? Why marine bird and mammal populations fluctuate in the North Pacific. In: Halloway G, Muller P, Henderson D (eds) Biotic impacts of extratropical climate change in the Pacific. University of Hawaii, Honolulu, p 109-119

* Springer AM, Byrd GV, Iverson SJ (2007) Hot oceanography: planktivorous seabirds reveal ecosystem responses to warming of the Bering Sea. Mar Ecol Prog Ser 352: 289-297

Stoffel MA, Nakagawa S, Schielzeth H (2017) An introduction to repeatability estimation with rptR. https://cran.rproject.org/web/packages/rptR/vignettes/rptR.html

Storer RW (1987) The possible significance of large eyes in the red-legged kittiwake. Condor 89:192-194

Strong RJ, Pereira MG, Shore RF, Henrys PA, Pottinger TG (2015) Feather corticosterone content in predatory birds in relation to body condition and hepatic metal concentration. Gen Comp Endocrinol 214:47-55

* Symonds MRE, Moussalli AE (2011) A brief guide to model selection, multimodel inference and model averaging in behavioural ecology using Akaike's information criterion. Behav Ecol Sociobiol 65:13-21

Tappa JD, Romano MD (2017) Biological monitoring at St. George Island, Alaska in 2016. US Fish and Wildlife Service, Alaska Maritime Wildlife Refuge, Homer, AK

* Thompson DWJ, Wallace JM (1998) The Arctic Oscillation 
signature in the wintertime geopotential height and temperature fields. Geophys Res Lett 25:1297-1300

Wang J, Hu H, Mizobata K, Saitoh S (2009) Seasonal variations of sea ice and ocean circulation in the Bering Sea: a model-data fusion study. J Geophys Res 114:C02011

Will AP, Suzuki Y, Elliott KH, Hatch SA, Watanuki Y, Kitaysky AS (2014) Feather corticosterone reveals developmental stress in seabirds. J Exp Biol 217:2371-2376

Will A, Watanuki Y, Kikuchi DM, Sato N and others (2015) Feather corticosterone reveals stress associated with dietary changes in a breeding seabird. Ecol Evol 5: 4221-4232

Editorial responsibility: Kyle Elliott,

Sainte-Anne-de-Bellevue, Québec, Canada
Wingfield JC, Farner DS (1975) The determination of five steroids in avian plasma by radioimmunoassay and competitive protein-binding. Steroids 26:311-327

* Yamamoto T, Kokubun N, Kikuchi DM, Sato N and others (2016) Differential responses of seabirds to environmental variability over 2 years in the continental shelf and oceanic habitats of southeastern Bering Sea. Biogeosciences 13:2405-2414

* Yang G, Li C, Guilini K, Wang X, Wang Y (2017) Regional patterns of $\delta^{13} \mathrm{C}$ and $\delta^{15} \mathrm{~N}$ stable isotopes of size-fractionated zooplankton in the western tropical North Pacific Ocean. Deep Sea Res I 120:39-47

Submitted: June 23, 2017; Accepted: January 31, 2018

Proofs received from author(s): March 13, 2018 